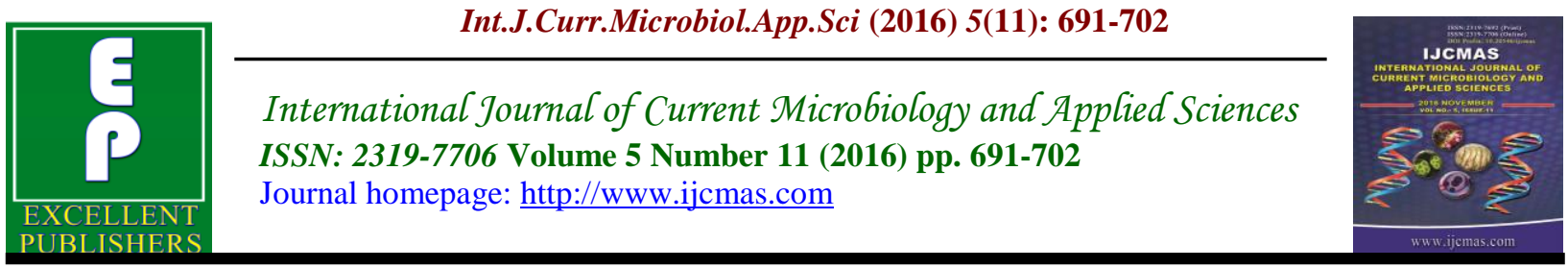

Original Research Article

http://dx.doi.org/10.20546/ijcmas.2016.511.080

\title{
Amplitude Modulated Waves as a Promising Tool for Food Preservation
}

\author{
Mohamed A. EL-Hag ${ }^{1 *}$, Eman F. Sharaf ${ }^{2}$ and Medhat A. El-Naggar ${ }^{3}$ \\ ${ }^{1}$ Biophysics Department, Faculty of Science, Cairo University, Giza, Egypt \\ ${ }^{2}$ Department of Botany and Microbiology, Faculty of Science, Cairo University, Giza, Egypt \\ ${ }^{3}$ Agricultural Research Centre, Plant pathology Institute, Giza, Egypt \\ *Corresponding author
}

Keywords

Food preservation, Biological effects, Electromagnetic waves, Asperagillus flavus, aflatoxins, Fungi.

\section{Article Info}

Accepted:

26 October 2016

Available Online:

10 November 2016

\section{A B S T R A C T}

The present work was directed to study the possibility of using Amplitude Modulated Waves (AMW) in food preservation. The effect of AMW on the growth and, in vitro, production of aflatoxins by some fungal species isolated from stored kidney bean seeds was investigated. Eight fungal genera comprising 11 species were isolated from 4 months stored kidney bean seeds. Genus aspergillus was the most dominant followed by Pencillium puberulum (RD. $62.8 \%$ and $19.2 \%$ of the total count, respectively). Aspergillus flavus (A. flavus) was the incomparable highly frequent species on the isolation plates. It constituted $35.6 \%$ of the total count. Only two isolates of A. flavus $\left(\mathrm{I}_{1}\right.$ and $\left.\mathrm{I}_{2}\right)$ were found to produce aflatoxins in vitro, of the type $B_{2}, G_{1}$ and $G_{2}$ in variable amounts. Exposure of the two isolates to amplitude modulated waves (AMW) for two hours at different frequencies inhibited spore germination and mycelia dry weight, irrespective of the wave frequency. The greatest inhibition was recorded at frequency of $10 \mathrm{~Hz}$ which completely suppressed the production of all types of aflatoxins. RAPD-PCR molecular analysis for aflatoxins producing fungi revealed relative changes in the position and number of some bands in DNA profile of both isolates, after treating with AMW at $10 \mathrm{~Hz}$. Cluster analyses for PCR products revealed a decreased genetic similarity level between the two exposed isolates and their respective nontreated controls.

\section{Introduction}

Fungal infection is one of the greatest problems facing storage of foods. Early in 1969, Christensen and Kaufman approved that seeds are subject for fungal contamination during storage which may destroy or at least devaluate them. Droby (2006) and Zhu (2006) estimated that about 20 up to $25 \%$ of fruits are damaged due to post-harvest handling and storage. Fungal infections of fruits may occur during growing, harvesting, handling, transport and storage (Bamidele et al., 2012). Furthermore, some of these fungi produce serious carcinogenic mycotoxins (Smith and Ross, 1991). One of these toxins is aflatoxins which are produced by certain species of Aspergillus like A. flavus and A. parasiticus (Palmgren and Ciegler, 1983; Samson and Frisvad, 1990; Trucksess et al., 2002). Accordingly, destruction of 
aflatoxigenic fungi in stored foods is an urged problem. This could be achieved through different methods such as preservatives (Ji et al., 2004), fungicides or essential oils (Jain and Jain, 2001) and gamma radiation (Shahhoseini, 1998). But the traditional methods of food preservation always have their own problems. Sometimes cause loss of sensitive nutrients, denaturation of proteins as well as change of structure, color and/or taste (Bamidele et al., 2012). Additionally, the formation of undesirable substances is possible (Lipiec et $a l .$, 2004). Therefore, developing new nonthermal safe methods for food preservation is not luxuriousness but it becomes a must.

Recently, the possible use of electromagnetic waves for inhibiting fungal growth have been investigated and proofed in many studies (Ramsted et al., 2000; Zhang et al., 2002; Rizk, 2003; Fadel et al., 2009; Bamidele et al., 2012; Ivona et al., 2015). Electromagnetic waves are nonionizing radiation proved to affect some physiological activities of living organisms (Piskorz-Binczycka et al., 2003; Maxim et al., 2004; Aronsson et al., 2005). Such effects are found to be time, frequency and intensity dependent (Grahl and Markel, 1996; MacGregor et al., 2000; Bamidele et al., 2012).

The present study is one of the efforts devoted to investigate the possible use of Amplitude Modulated Waves (AMW) as a non-thermal safe technique for food preservation.

\section{Materials and Methods}

\section{Samples}

Kidney bean seeds (Phaseoulus vulgaris L.), previously stored for four months were used in this study. Samples of four different cultivars (Nebraska, Giza 3, Giza 6 and Serbo) were obtained from agricultural research center, Giza, Egypt.

\section{Fungal isolation}

The isolation of seed born fungi was carried out according to Christensen (1957). The developing fungal colonies were counted then identified according to Raper and Fennell (1965); Ellis (1971); Barnett and Hunter (1987); Klich and Pitt (1988).

\section{Aflatoxins production}

\section{Qualitative estimation for aflatoxins production}

Aspergillus flavus, isolated from kidney bean seeds in the last procedure, were studied for aflatoxin production. The isolates were grown on SMKY agar medium, and then incubated for 10 days at temperature of $27^{\circ} \mathrm{C}$. The ability of the separate colonies to produce aflatoxins was examined by using ultraviolet light of wavelength $365 \mathrm{~nm}$ through checking the fluorescence around each colony. Only two isolates of Aspergillus flavus were found to be able to produce aflatoxins.

\section{Quantitative estimation for aflatoxins production}

Fungal discs (1 cm, 5 days old) of the aflatoxins producing isolates were used to inoculate flasks containing $5050 \mathrm{~mL}$ SKMY medium, separately. Three replicates were prepared for each isolates, and then incubated at $27^{\circ} \mathrm{C}$ for 10 days.

Aflatoxins were extracted according to Davis et al., (1966) from the filtirate. Standards of aflatoxins $B_{1}, B_{2}, G_{1}$ and $G_{2}$ (Sigma) were used to determine the type of aflatoxins produced by using thin layer 
chromatography (TLC). While, the amount of aflatoxins produced was estimated using high performance thin layer chromatography (HPTLC) apparatus (Bio Doc Analysis, Germany).

\section{Exposure facility}

The two aflatoxins producing isolates of $A$. flavus were grown on Czapek-Dox's agar medium for 5 days at temperature of $27^{\circ} \mathrm{C}$, then exposed to AMW with different frequencies $(1,5,10,15$ and $20 \mathrm{~Hz})$ for 2 hrs. The samples were exposed to the AMW through two parallel cupper disk electrodes, each of diameter $8 \mathrm{~cm}$. The modulating waveform was square and the carrier frequency was $10 \mathrm{MHz}$ sine wave. The wave carrier was generated by a wave generator model AFG 310 manufactured by Sony Tektronics, Japan, and the modulating wave was generated by synthesized arbitrary generator type TTi TGA 1230. The amplitude of the wave carrier was $20 \mathrm{~V}$ and the modulating depth was $\pm 2 \mathrm{~V}$ (Fadel et al., 2009).

\section{Spore germination}

Spores of both exposed and unexposed isolates were examined for germination using slides with central cavity. The exposed ones were examined directly after exposure to AMW. Spore suspension was prepared in sterile distilled water, then $0.1 \mathrm{~mL}$ of the suspension was introduced into the slides cavities (triplicates, 10 microscopic field per slide) and covered with a sterile edge greased cover glass. Then incubated at 28 ${ }^{\circ} \mathrm{C}$ for a suitable period of time and the germinated spores were counted and the percentage germination of spores was calculated and compared to that of the unexposed control.

\section{Mycelial dry weight}

Mycelia dry weight was determined using Czapek-Dox's medium. Discs of diameters 1 $\mathrm{cm}$ from both exposed and unexposed fungi were inoculated into flasks containing 50 $\mathrm{mL}$ of the medium (triplicates for both samples). The flasks were incubated for 7 days at temperature of $27{ }^{\circ} \mathrm{C}$. The mycelia, for both exposed and unexposed ones, were harvested, dried at $60{ }^{\circ} \mathrm{C}$ and their dry weight was determined and compared.

\section{Molecular analysis for aflatoxins producing isolates}

DNA Extraction: fungal discs of $1 \mathrm{~cm}$ in diameter, and 5 days old of both isolate of $A$. flavus just after exposure to AMW, as well as, unexposed (control) one were used to inoculate different flasks, each containing 50 mL of Czapel-Dox's medium. Flasks were prepared in triplicates for each sample. The flasks were incubated for 5 days. The mycelia were separated and washed then DNA was extracted from $50 \mathrm{mg}$ fresh mycelium using Qiagen Kit and dissolved in $100 \mu \mathrm{L}$ buffer of PH 8.0 (Pieter et al., 1995).

\section{Random amplified polymorphic DNA (RAPD) - PCR technique}

$5 \mu \mathrm{L}$ of the previously extracted genetic material were amplified using polymerase chain reaction (PCR) model UNII, Biometra, Germany (Pieter et al., 1995). The PCR reaction mixture (Taq-DNA polymerase and dNTP) and the primer sequence (5'd[GTAGACCCGT]3') were used for amplification according to the following PCR cycling conditions (45 cycles). 
1- Denaturation at $95{ }^{\circ} \mathrm{C}$ for 1 minute followed by primer annealing at $36{ }^{\circ} \mathrm{C}$ for 1 minute.

2- Extension at $72{ }^{\circ} \mathrm{C}$ for 2 minutes and final extension at $72^{\circ} \mathrm{C}$ for 5 minutes, then, cooling at $4{ }^{\circ} \mathrm{C}$.

Gel electrophoresis: The PCR products were electrophorated in 1\% agarose gel, using WIDE-mini-sub cell GT, Bio-Rad electrophoresis and stained with ethidium bromide. The gel was scanned for bands using gel documentation program (Cairns and Murray, 1994) and the level of similarity was calculated through cluster analysis.

\section{Statistical analysis}

Analysis of variance was detected to evaluate the significance between means using SPSS statistical software $(\mathrm{P}<0.01)$

\section{Results and Discussion}

Four cultivars of kidney bean seeds (Nebraska, Giza 3, Giza 6 and Serbo) were examined for seed born fungi after storage of 4 months. Eight fungal genera with a total of 655 colonies/seed, comprising 11 species, were isolated from them (Table 1). The most prevalent species was Aspergillus, constituting $62.8 \%$ of the total population, followed by Penicillium puberulum with $19.2 \%$ of the total populations. A. flavus was the most dominant species in the 4 cultivars and recorded the highest relative density (RD $35.6 \%$ of the total count). Lower densities were observed for A. niger, A. ochraceous and A. parasiticus (RD 17.7, 6.9 , and $2.6 \%$, respectively). Alternaria alternate came next and it accounted for 5.6 $\%$ of the total count. Also Mucor hiemalis and Nigrospora sp. were isolated from kidney bean seeds, each with RD less than $5 \%$ of the total count. The other species, Epicoccum purpurascens, Chaetomium globosum and Trichothecium roseum were detected occasionally and all of them constituted $3.2 \%$ of the isolations.

Fungal growth in stored seeds and grains is affected by water and temperature (Magan and Lacey, 1988) these fungi produce mycotoxins (Smith and Rose, 1991) which represent threats not only to vitality of seeds but also to the health of animals and humans feed on them. The prevalence of some members of Aspergilli and Penicillia in stored seeds and grains is well known worldwide (Smith and Ross, 1991; Abou ElElla, 2002). Also, the most dominant $A$. flavus produces exudates which increase seed moisture content and thus improves the growth conditions for other species (Christensen, 1972).

From the table it is clear that A. flavus achieved the incomparable highest total count on the isolation plates. Therefore, it was chosen to be examined for in vitro production of aflatoxins. Screening of all isolates of A. flavus (233 isolates) for qualitative production of aflatoxins revealed that two isolates only (A. flavus $\mathrm{I}_{1}$ and $A$. flavus $\mathrm{I}_{2}$ ) produce aflatoxins of the types $\mathrm{B} 2$, G1 and G2 (Figure 1).

The total amount of aflatoxins produced by A. flavus $\mathrm{I}_{1}$ and $\mathrm{I}_{2}$ is illustrated in Table 2. A. flavus is well known to produce aflatoxins (Palmgren and Ciegler, 1983) and the variability in the type and quantity of these toxins among strains has been established (Klich and Pitt, 1988; Cotty, 1989; Abramson and Clear, 1996; Ji et al., 2004).

In the present study, fungal cultures of the afltoxin producing isolates of A. flavus were exposed to AMW with different frequencies. All the applied frequencies exhibit a variable degree of inhibition for growth criteria, except at $1 \mathrm{~Hz}$ which showed nonsignificant effect $(\mathrm{P}<0.01)$ on either percentage spore germination or mycelia dry 
weight (Figures 2 and 3, respectively). The maximum inhibition has been observed when samples were exposed to AMW of frequency $10 \mathrm{~Hz}$. However, no linear correlation could be observed between the frequency of the applied waves and the degree of inhibition occurred. Similar results were observed by Geveke and Brunkhorst (2003). The response of both isolates after exposure to AMW was nearly similar. Likely, electromagnetic waves suppressed the germination of the sclerotia for both Sclerotium rolfsii (Rizk, 2003) and Sclerotium cepivorum (Fadel et al., 2009), as well as, inhibit the mycelia growth (Rizk, 2003) while, AMW accelerated the spore germination and mycelia growth of Penicillium claviforme (Piskorz-Binczycka et al., 2003).

Additionally, electromagnetic waves induced great reduction in viable cells of microorganisms depending on the wave frequency, time of exposure and/or the exposed organism (Grahl and Markl, 1996). Such reduction might be due to breakdown of cell membrane (Calderon-Miranda et al., 1999; Schoenbach et al., 2000; Dunne, 2000; Oshima and Sato, 2004; Aronsson et al., 2005).

It is clear from the given data that, the maximum effect of AMW, on both isolates of A. flavus, occurred at frequency of $10 \mathrm{~Hz}$. Therefore, its effect on aflatoxins production was investigated. The data showed that, the ability of both isolates to produce aflatoxins was highly suppressed when exposed to AMW with frequency of 10 for 2 hrs (Figure 4), compared to that for unexposed ones (Figure 1). This was evident from the disappearance of the bands of all types of aflatoxins (B2, G1 and G2). Such response indicates that AMW with frequency of 10 $\mathrm{Hz}$ may resonate and interferes with physiological process involved in aflatoxins production.

Table.1 Total count and relative density (RD\%) of fungi associated with four cultivars of kidney bean seeds after storage for 4 months.

\begin{tabular}{|c|c|c|c|c|c|c|c|c|}
\hline \multirow{2}{*}{\multicolumn{2}{|c|}{ Fungal species }} & \multicolumn{4}{|c|}{ Kidney bean cultivars } & \multirow{3}{*}{$\begin{array}{c}\begin{array}{c}\text { Total } \\
\text { count }\end{array} \\
233\end{array}$} & \multirow{2}{*}{\multicolumn{2}{|c|}{$\mathrm{RD} \%$}} \\
\hline & & \multirow{2}{*}{$\frac{\text { Nebraska }}{43}$} & \multirow{2}{*}{$\begin{array}{c}\text { Giza } 6 \\
63 \\
\end{array}$} & \multirow{2}{*}{$\frac{\text { Serbo }}{48}$} & \multirow{2}{*}{$\frac{\text { Giza } 3}{79}$} & & & \\
\hline \multirow{4}{*}{$\begin{array}{c}\text { Aspergillus } \\
\text { spp. }\end{array}$} & A. flavus & & & & & & 35.6 & \multirow{4}{*}{62.8} \\
\hline & A. niger & 35 & 58 & 0 & 23 & 116 & 17.7 & \\
\hline & A. ochraceous & 11 & 21 & 3 & 10 & 45 & 6.9 & \\
\hline & A. parasiticus & 0 & 13 & 2 & 2 & 17 & 2.6 & \\
\hline \multicolumn{2}{|c|}{ Penicillium puberulum } & 43 & 10 & 46 & 27 & 126 & & \\
\hline \multicolumn{2}{|c|}{ Alternaria alternate } & 0 & 0 & 26 & 11 & 37 & & \\
\hline \multicolumn{2}{|c|}{ Nigrospora $s p$} & 1 & 10 & 10 & 8 & 29 & & \\
\hline \multicolumn{2}{|c|}{ Epicoccum purpurascens } & 0 & 0 & 0 & 2 & 2 & & \\
\hline \multicolumn{2}{|c|}{ Chaetomium globosum } & 0 & 8 & 0 & 0 & 8 & & \\
\hline \multicolumn{2}{|c|}{ Mucor hiemalis } & 0 & 13 & 2 & 16 & 31 & & \\
\hline \multicolumn{2}{|c|}{ Trichothecium roseum } & 9 & 0 & 0 & 2 & 11 & & \\
\hline \multicolumn{2}{|c|}{ Total } & 142 & 196 & 137 & 180 & 655 & & \\
\hline
\end{tabular}


Table.2 Quantitative estimation for afltoxin production ( $\mu \mathrm{g} / 50 \mathrm{~mL}$ medium) by the two isolates of A. flavus.

\begin{tabular}{|c|c|c|c|c|}
\hline \multirow{2}{*}{ Isolates } & \multicolumn{3}{|c|}{ Type of aflatoxin } & \multirow{2}{*}{ Total } \\
\cline { 2 - 4 } & $\mathrm{B} 2$ & $\mathrm{G} 1$ & $\mathrm{G} 2$ & 41.85 \\
\hline A. flavus $\mathrm{I}_{1}$ & 14.22 & 13.77 & 13.86 & 36.35 \\
\hline A. flavus $\mathrm{I}_{2}$ & 10.00 & 13.97 & 12.38 & \\
\hline
\end{tabular}

Fig.1 Qualitative screening for aflatoxin production by two isolates of A. flavus. Lane 1: A. falvus I1, Lane 2: A. flavus I2, Lane 3: Aflatoxins standard.

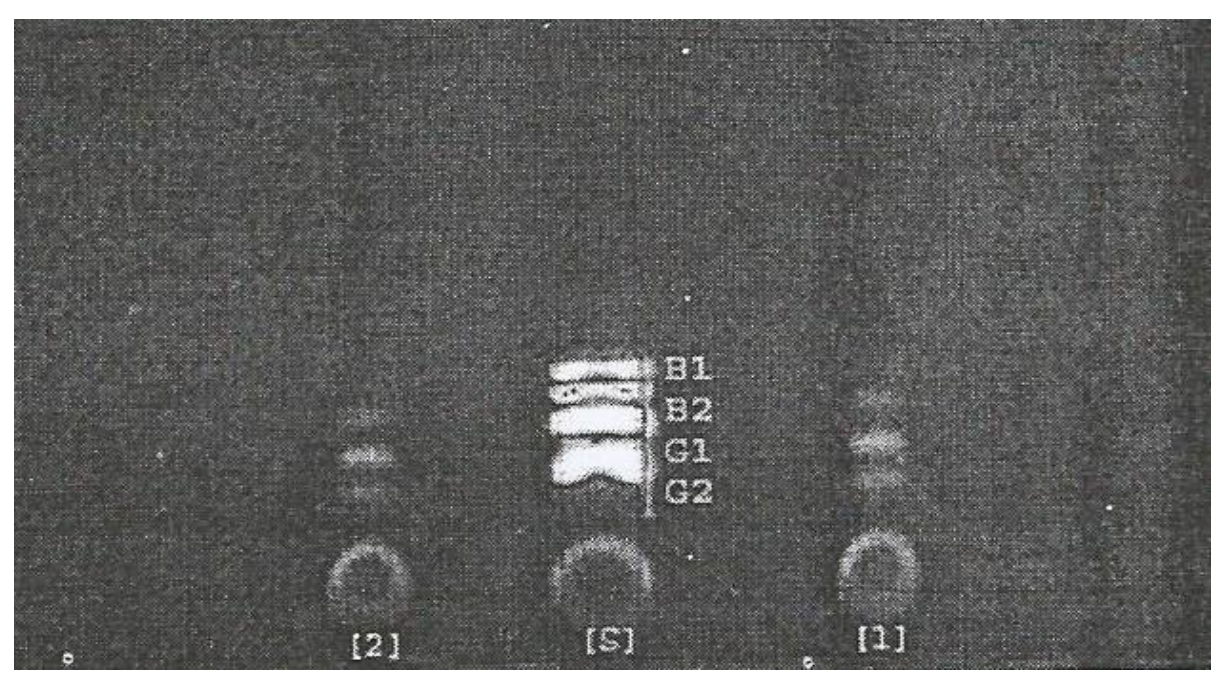

Fig.2 Effect of AMW with different frequencies on the percentage germination of A. flavus isolates.

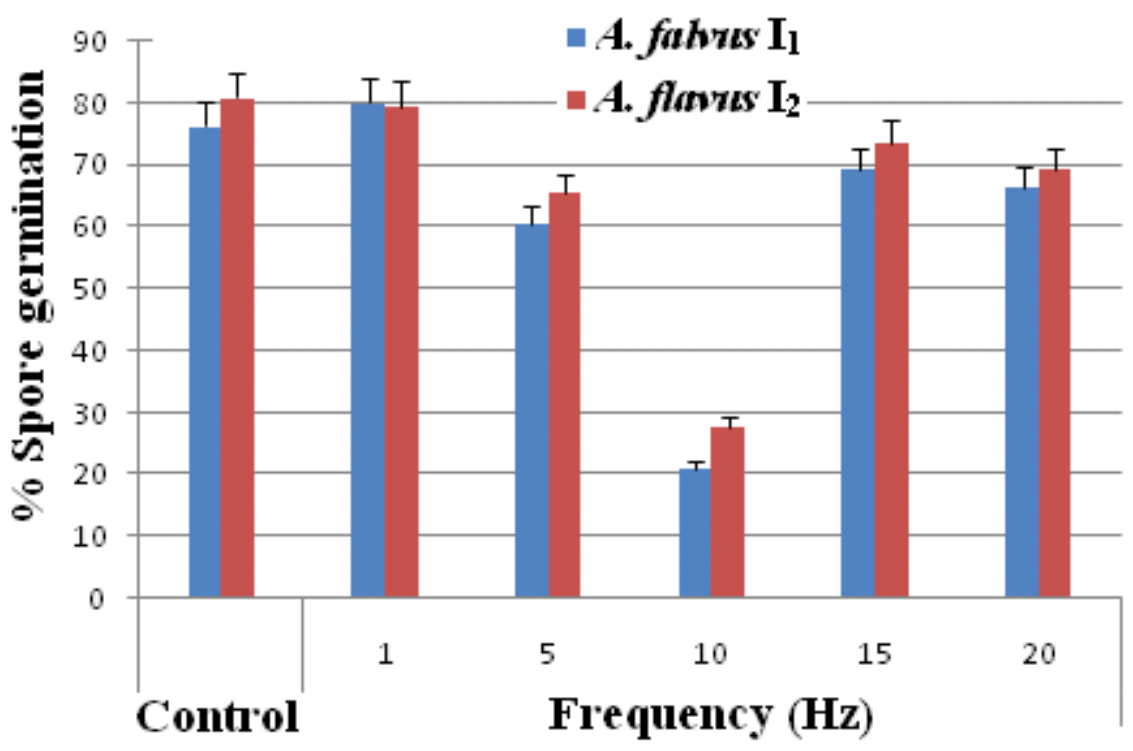


Fig.3 Effect of AMW with different frequencies on the mycelia dry weight (mg/flask) of A. flavus isolates

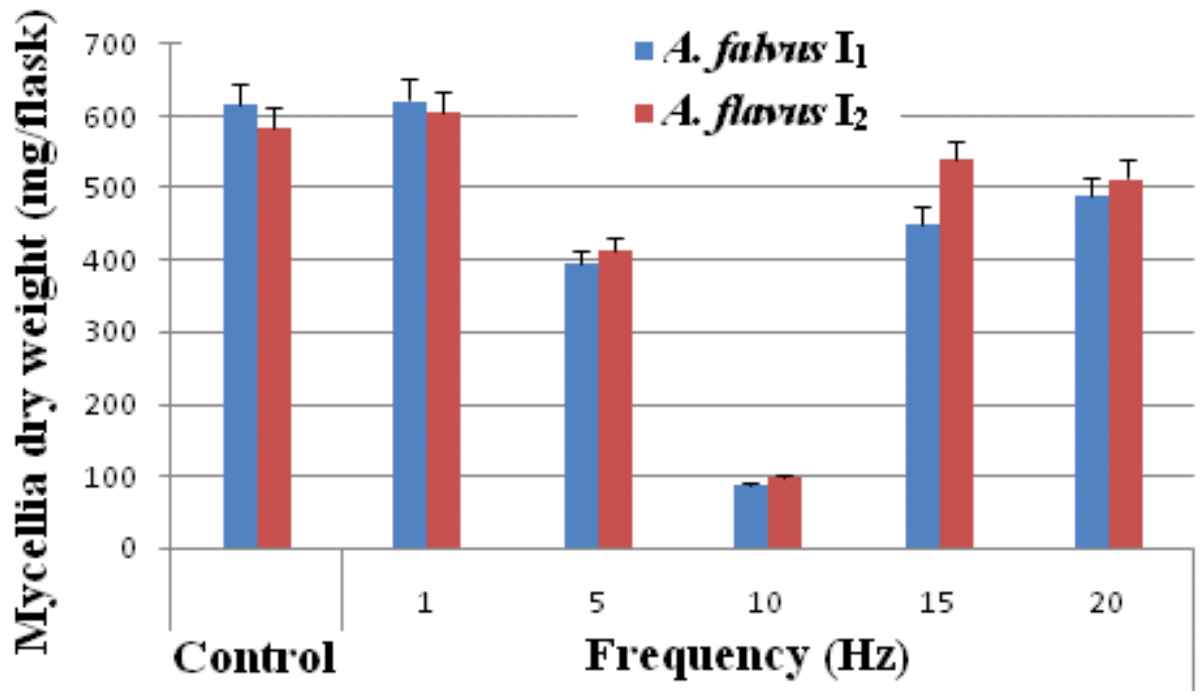

Fig.4 Aflatoxins production by A. flavus I1 (Lane 1) and A. flavus I2 (Lane 2) after exposure to AMW with frequency $10 \mathrm{~Hz}$ for two hs, as compared to standard (Lane S).

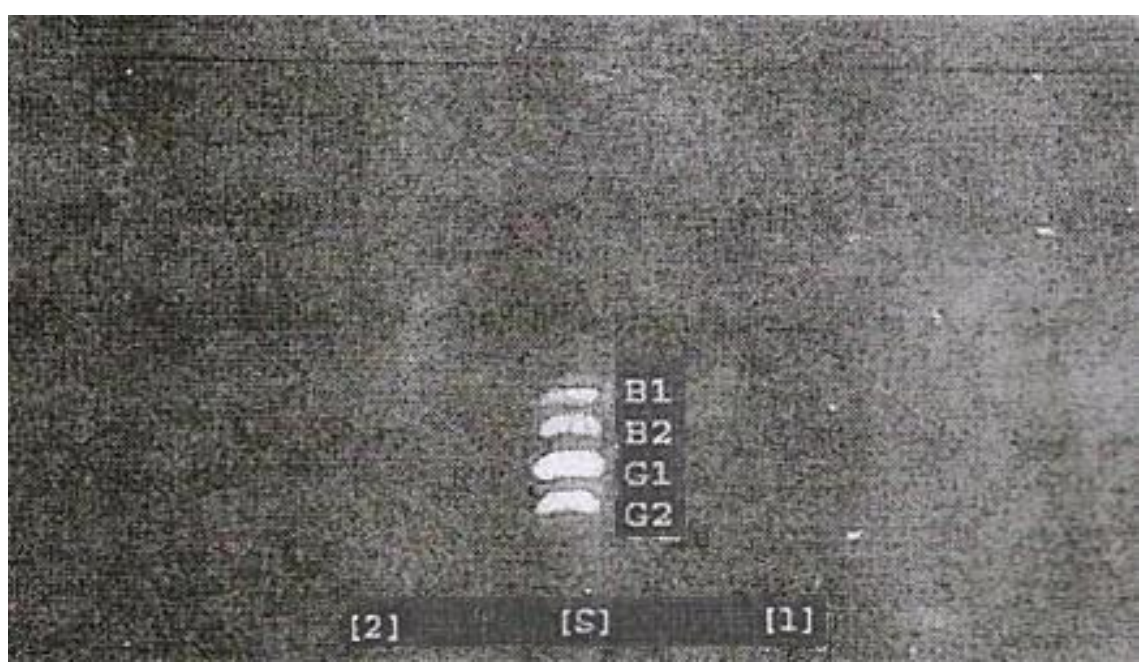


Fig.5 Gel electrophoresis of PCR Products of control (unexposed) isolates of A. flavus I1 (Lane 1) and A. flavus I2 (Lane 2) as compared to exposed ones, A. flavus I1 (Lane 3) and A. flavus I2 (Lane 4)

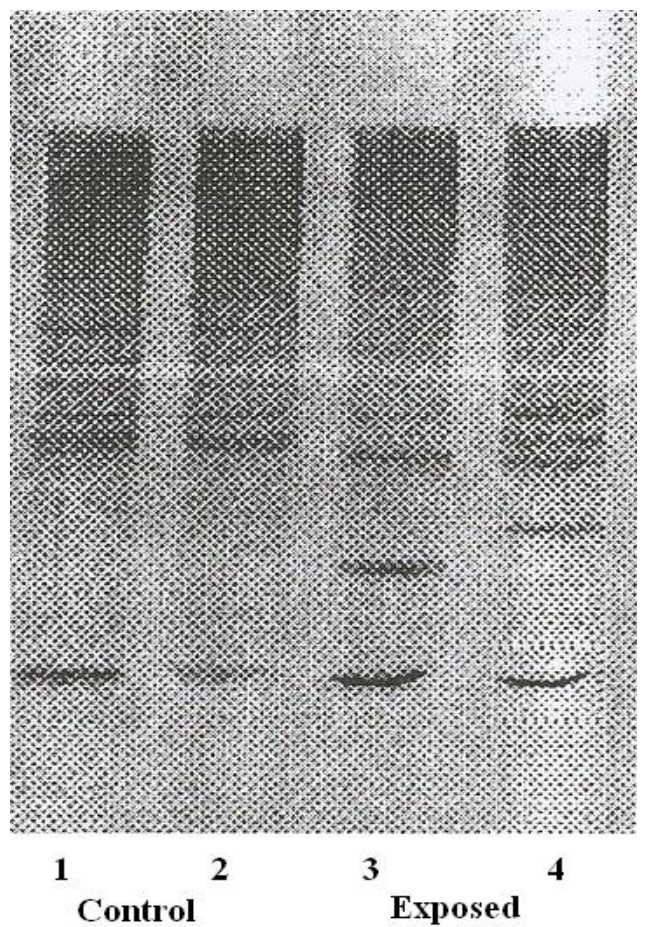

Fig.6 Genetic similarity levels between control (unexposed) isolates of $A$. flavus I1 (Lane 1) and A. flavus I2 (Lane 2) as compared to exposed ones, A. flavus I1 (Lane 3) and A. flavus I2 (Lane

4)

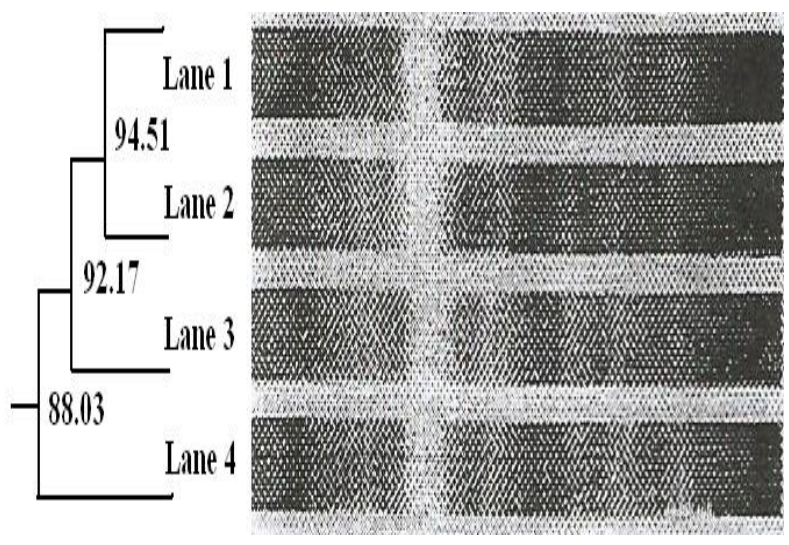

Similar effect was observed by Eisa et al., (2002), when exposed corn grains inoculated with A. flavus to electromagnetic waves reduced, in situ, aflatoxins production without affecting grain quality. A similar inhibiting effect for AMW was observed by
EL-Hag (2003), on his study on Pseudomonas aeruginosa. The study showed that AMW suppressed the toxins production by Pseudomonas aeruginosa when exposed to AMW of frequency of $0.5 \mathrm{~Hz}$. 
Molecular analysis for aflatoxin producing isolates, exposed to AMW of frequency 10 $\mathrm{Hz}$, was carried out after DNA amplification by PCR technique (Figure 5). The results revealed relative changes in the position and number of some bands in the DNA profile of both isolates, which were almost similar. These observations may be denoting the interference of the AMW at this frequency with gene expression for aflatoxin production. Furthermore, genetic similarity level (Figure 6) between A. flavus $\mathrm{I}_{1}$ and its comparable unexposed one was reduced to $92.17 \%$ (7.83\% dissimilarity), whereas that of exposed $A$. flavus $\mathrm{I}_{2}$ was reduced to $88.03 \%$ (11.97\% dissimilarity).

In this connection, recent studies revealed that electromagnetic waves induce damage for cell structure and composition (Bamidele et al., 2012) starting from cell membrane (Bersani et al., 1997; Schoenbach et al., 2000) extending to the cytoplasm and nucleus (Hill, 1998). Exposure to extremely low frequencies EMW cannot induce direct damage to DNA, due to its low energy, but it may affect general and specific gene expression (Smiko and Mattson, 2004; Fadel et al., 2009). In addition, Fadel et al., (2009) suggested that this genetic effect may be attributed to bioelectric resonance interference resulted in the deterioration and/or alteration of the DNA genetic properties.

In conclusion, it may be concluded from the present study that, AMW may be a promising non-thermal safe technique for inactivation of harmful pathogenic moulds and their abilities to produce mycotoxins, aflatoxin included, in stored foods and grains instead of the health risks and other problems resulting from traditional methods of preservation. Future work on the possible effects of such waves on the viability of the treated grains is recommended.

\section{References}

Abou El-Ella, M.F. 2002. Studies on maize grains deterioration under Egyptian conditions. Ph.D. Thesis, Faculty of Agriculture, Moshtohor, Zagazig University, Egypt.

Abramson, D., and Clear, R.M. 1996. A convenient method for assessing mycotoxin production in cultures of Aspergilli and Pencilli. J. Food Prot. 59: 642-664.

Aronsson, K., U. Ronner and Borch, E. 2005. Inactivation of Escherichia coli, Listeria innocua and Saccharomyces cerevisiae in relation to membrane permeabilization and subsequent leakage of intracellular compounds due to pulsed electric field processing. Int. J. Food. Microbiol. 99: 19-32.

Bamidele, J.A., O.C. Akinkunmi and Adedayo, K.D. 2012. Effect of electromagnetic field on the spoilage fungi of some selected edible fruits in southwestern Nigeria. $J$. Microbiol. Biotechnol. Food Sci., 2(2): 701-712.

Barnett, H.L., and Hunter, B.B. 1987. Illustrated genera of imperfect fungi. $4^{\text {th }}$ ed., Macmillan Publ. Co. New York.

Bersani, T., I. Marinelli, A. Ogmbene, S. Cecchi, S. Sahti, S. Squarzohi and Maraldi, N.M. 1997. Intermembrane protein distribution in cell cultures is affected by $50 \mathrm{~Hz}$ pulsed magnetic fields. Bioelectromagnetics, 18: 463-469.

Cairns, M., and Murray, V. 1994. Rapid silver staining and recovery of PCR products separated on polyacrylamide gels. Biotechniques, 17: 915-917.

Calderon-Miranda, M.L., G.V. Barbosa-Canovas and Sawanson, B.G. 1999. Inactivation of Listeria innocua in skim milk by pulsed electric fields and nisin. Int. J. Food Microbiol. 51: 19-30.

Christensen, C.M., 1957. Deterioration of stored grains by fungi. Bot. Rev. 23: 108-134.

Christensen, C.M., 1972. Microflora and seed deterioration. In: Viability of seeds. Roberts, E.H. (Ed.), Chapman and Hall, London.

Christensen, C.M., and Kaufman, H.H. 1969. 
Grain storage: The role of fungi in quality loss, Minneapolis, University of Minnesta press.

Cotty, P.J., 1989. Virulence and cultural characteristics of two Aspergillus flavus strains pathogenic on cotton. Phytopathol., 79: 808-814.

Davis, N.D., U.L. Diener and Eldridge, D.W. 1966. Production of aflatoxins B1 and G1 by Aspergillus flavus in a semi-synthetic medium. Appl. Microbiol., 14: 379-381.

Droby, S., 2006. Improving quality and safety of fresh fruits and vegetables after harvest by the use of biocontrol agents and natural materials. African J. Microbiol., 709: 4551.

Dunne, C.P. 2000. Updatrs on new processin technologies. $20^{\text {th }}$ Ann. Conf. On: The responsabilities of thermal processing specialists, Crystal city, Av, Nov. 15.

Eisa, N.A., F.M. Ali, G.M. Habbaa, S.K. AbdelReheem and Abou-Ella, M.F. 2002. Pulsed electric field (PEF) as a promsing technology for destroying aflatoxins production potentiality of Apergillus flavus in stored corn grains. Proceeding of the second conference on Foodborne Contamination and Egyptians Health, ElMansoura, Egypt.

EL-Hag, M.A., 2003. Effect of ELF electric field on the biophysical properties and biological activity of some microorganisms. Ph.D. Thesis, Faculty of Science, Cairo University, Egypt.

Ellis, M.B., 1971. Dematiaceous hyphomycetes. Commonw. Mycol. Inst. Kew. Pp. 608.

Fadel, M., Ali, M.A. Ahmed and El Hag, M.A. 2009. Control of Sclerotium cepivorum (Allium White Rot) activities by electromagnetic waves at resonance frequency. Australian J. Basic and Appl. Sci., 3(3): 1994-2000.

Geveke, D.J., and Brunkhorst, C. 2003. Inactivation of Saccharomyces cerevisiae with radiofrequency electric fields. $J$. Food Prot., 66: 1712-1715.

Grahl, I.T., and Markl, I.H. 1996. Killing of microorganisms by pulsed electric fields. App. Microbial. Biotech., 45: 148-157.

Hill, S.M., 1998. Receptor crosstalk: Communication through cell signalling pathways. Bioelectromagnetics, 16: $207-$ 210.

Malíková, I., L. Janoušek, V. Fantova, J. Jíra and Kř́ha V. 2015. Impact of low frequency electromagnetic field exposure on the Candida Albicans. J. Electrical Engineering, 66(2): 108-112.

Jain, N.K., and Jain, P.K. 2001. A comparative study of some essential oils and fungicides as seed dressers against Aalternaria tenuis in Withania somnifera. J. Med. Arom. Plant Sci., 22/23: 192-193

Ji, L.L., Y.C. Song and Tan, R.X. 2004. A potent feed preservative candidate produced by Calcarisporium $s p$. an endophyte residing in star grass (Cynodon dactylon). J. Appl. Microbiol. 96: 352358.

Klich, M.A., and Pitt, J.I. 1988. A laboratory guide to common aspergillus species and their teleomorphs. North Ryde, N.S.W.: Commonwealth Scientific and Industrial Research Organisation, Division of Food Processing.

Lipiec, J., P. Janas and Barabasz, W. 2004. Effect of oscillating magnetic field pulses on the survival of selected microorganisms. Int. J. Agrophys., 18: 325-328.

MacGregor, S.J., O. Farish, R. Fouracre and Rowan, N.J. 2000. Inactivation of pathogenic and spoilage microorganisms in a test liquid using pulsed electric fields. IEEE Transactions on Plasma Sci., 28(1): 144-149.

Maxim, P.G., J.L. Carson, S. Ning, S.J. Knox, A.L. Boyer, C.P. Hsu, D.A. Benaron and Walleezek, J. 2004. Enhanced effectiveness of radiochemotherapy with tirapazamine by local application of electric pulses to tumors. Rad. Res., 162: 185-193.

Megan, N., and Lacey, J. 1988. Ecological determination of mould growth in stored grains. Int. J. Food Microbiol., 7: 245256.

Oshima, T., and Sato, M. 2004. Bacterial sterilization and intracellular protein release by a pulsed electric field. $A d v$. Biochem. Eng. Biotechnol., 90: 113-133.

Palmgren, M.S., and Ciegler, A. 1983. 
Aflatoxins. In: plant and fungal Toxins. Keeler, R.F., and Tu, A.T. (Eds.), Marcel Decker, New York.

Pieter, V., R. Hogers, M. Bleeker, M. Reijans, T.V.D. Lee, M. Hornes, A. Friters, J. Peleman, M. Kuiper and Zabeau, M. 1995. AFLP a new technique for DNA fingerprint. Nucleic Acids Res., 23: 44074414.

Piskorz-Binczycka, B., J. Fiema and Nowak, M. 2003. Effect of the magnetic field on the biological clock in Penicillium claviforme. Acta Biol. Cracov. Series Botanica, 45: 111-116.

Ramsted, S., C.M. Futsaether and Johanson, A. 2000. Effect of $50 \mathrm{~Hz}$ electric currents and magnetic fields on the prokaryote,Propionibacterium acnes. Int. J. Syst. Eco. Microbiol., 50: 417-427.

Raper, K.B., and Fennell, D.I. 1965. The Genus Aspergillus. William and Wilkins, Baltimore.

Rizk, M.A. 2003. Possible control of sugar beet pathogen Sclerotium rolfsii Sacc. by ELF Amplitude modulated waves. Pak. J. Biol. Sci., 6: 80-85.

Samson, R.S., and Frisvad, J. 1990. Taxonomic species concepts of hyphomycetes related to mycotoxins production. Proc. Jpn. Assoc. Mycotoxicol., 32: 3-10.

Schoenbach, K.H., R.P. Joshi, R.H. Stark and Dobbs, F.C. 2000. Bacterial decontamination of liquids with pulsed electric fields. IEEE Transactions on
Dielectrics and Electric Insulation, 7(5): 637-645.

Shahhoseini, G.H.R., 1998. Studying the application of gamma radiation in removing fungal contamination of poultry grain and the effect of this radiation on changing the immunity titer related to vaccinate SPF chickens. Sci. Bull. Atom. Energ. Iran, 17: 22-30.

Smiko, M., and Mattsson, M.O. 2004. Extremely low frequency electromagnetic fields as effectors of cellular responses in vitro:possible immune cell activation. $J$. Cell Biochem., 93: 83-92.

Smith, J.E., and Ross, K. 1991. The toxigenic Aspergillus. In: Mycotoxins and Animal Foods. Smith, J.E., and Henderson, R.S. (Eds.), CRC Press, Boca Raton.

Trucksess, M.W. M.A. Dombrink-Kurtzman, V.H. Tournas and White, K.D. 2002. Occurrence of aflatoxins and fumonisins in Incparina from Guatemala. Food Add. Contam., 19: 671-675.

Zhang, S., W. Wei, J. Zhang, Y. Mao, and Liu, S. 2002. Effect of static field on growth of Escherichia coli and relative response model of series piezoelectric quartz. Analyst, 127: 337-377.

Zhu, S.I. 2006. Non-chemical approaches to decay control in postharvest fruit. In: Advances in postharvest Technologies for Horticultural Crops. Noureddine, B., and Norio, S. (Eds.), Research Signpost, Trivandrum, India.

\section{How to cite this article:}

Mohamed A. EL-Hag, Eman F. Sharaf and Medhat A. El-Naggar. 2016. Amplitude Modulated Waves as a Promising Tool for Food Preservation. Int.J.Curr.Microbiol.App.Sci. 5(11): 691701. doi: http://dx.doi.org/10.20546/ijemas.2016.511.080 